\title{
Dual task interference in children from 8 to 12 years old Interferencia de las dobles tareas en niños de 8 a 12 años
}

\author{
*Adrià Marco-Ahulló, **Raúl Fernández, ***Gonzalo Monfort-Torres, **Pilar Bustillo-Casero, **Jose Luis \\ Bermejo, **Xavier García-Massó \\ *Vall d'Hebron Research Institute (España), **Universidad de Valencia (España), ***Florida Universitaria (España)
}

\begin{abstract}
The main aim of this manuscript was to analyze the effect of dual task and their difficulty on the motor and cognitive performance using a postural control and a memory tasks in middle childhood group ages children, establishing the differences between the effect of the tasks in the different age groups. The study sample was composed by one hundred and sixteen children, between 8 and 12 years old. The participants completed three single tasks and two dual-tasks. The postural single task (EO) consisted in maintain the balance in the bipedal stance position and two cognitive single tasks performed were the Backward Digit Span Test with 3-Digits sequences length and the Backward Digit Span Test 5-Digits sequences length. The dual-tasks were the combination of the postural task and the cognitive tasks. Regarding the postural control measurement, CoP signals were acquired with a Wii Balance Board. The analysis performed showed that the younger groups (8-9 years old) had worse punctuations in postural control variables in dual-task conditions than the older age groups (11-12 years old), especially than the 12 years old group. Regarding the effect of dual task in postural control, in all groups between 9 to 12 years old, higher postural control and stability were observed during the execution of the 5D dual-task than during the 3D task. Finally, no differences were found in the number of correct answers in the cognitive task when performing a single or dualtask, in any age group.
\end{abstract}

Keywords. Balance; memory; development.

Resumen. El objetivo principal de este manuscrito fue analizar el efecto de la doble tarea y su dificultad sobre el rendimiento motor y cognitivo mediante una tarea de control postural y otra de memoria en niños, estableciendo las diferencias entre el efecto de las tareas en los distintos grupos de edad. La muestra del estudio estuvo compuesta por ciento dieciséis niños, de entre 8 y 12 años de edad. Los participantes completaron tres tareas simples y dos tareas dobles. La tarea individual postural (EO) consistió en mantener el equilibrio en posición de bipedestación y las dos tareas individuales cognitivas realizadas fueron el Backward Digit Span Test con secuencias de 3 dígitos y el Backward Digit Span Test con secuencias de 5 dígitos. Las dobles tareas fueron la combinación de la tarea postural y las tareas cognitivas. En cuanto a la medición del control postural, las señales del CoP se adquirieron mediante una Wii Balance Board. El análisis realizado mostró que los grupos más jóvenes (8-9 años) obtuvieron peores puntuaciones en las variables de control postural en condiciones de doble tarea que los grupos de mayor edad (11-12 años), especialmente que el grupo de 12 años. En cuanto al efecto de la doble tarea sobre el control postural, en todos los grupos de 9 a 12 años se observó un mayor control postural y estabilidad durante la ejecución de la doble tarea 5D que durante la tarea 3D. Por último, no se encontraron diferencias en el número de respuestas correctas en la tarea cognitiva al realizar una tarea simple o dual, en ningún grupo de edad.

Palabras clave. Equilibrio; memoria; desarrollo.

\section{Introduction}

Childhood is a key period for the development of fundamental motor skills (Goodway \& Branta, 2003). These skills are classified in locomotor (e.g. running), manipulative (e.g. catching) and stability skills (e.g. balancing) (Lubans et al., 2010). Thus they are the cornerstone of more complex and specialized movement sequences required for the realization more complex actions (Clark \& Metcalfe, 2002). Therefore, the

Fecha recepción: 21-02-21. Fecha de aceptación: 14-06-21

PreferenciasAdrià Marco-AhullóSergio J. Ibáñez

adria.marco@vhir.org development of fundamental motor skills is necessary for adolescents to participate in more complex activities (Holfelder \& Schott, 2014).

Focussing in stability skills, it was believed that are performed automatically requiring minimal cognitive processing (Boonyong et al., 2012; Ebersbach et al., 1995). Currently, the scientific evidence seems to indicate that this fundamental motor skill is based on the interaction of dynamic sensorimotor processes and require of significant attentional demands (Boonyong et al., 2012; Shumway-Cook \& Woollacott, 2000). In daily life, the postural task is commonly paired with other motor or cognitive tasks (e.g., talking while standing or walking) (Palluel et al., 2010). Researchers use 
dual-task methodology to investigate the attentional demands of motor tasks or the effects of concurrent tasks on motor performance (Huang \& Mercer, 2001). There are many studies on dual-tasks in adults and its effects are being studied in children and adolescents (Arce-Cifuentes et al., 2020; Bustillo-Casero et al., 2017, 2020; Huang et al., 2003).

Some of the research carried out in children performing dual-task postulates that a cognitive task alters motor performance. Schmid et al. (2007), confirmed that a concurrent cognitive task influences postural control of 9 years old children. Blanchard et al. (2005) observed differences in the strategies of postural control in children of 8 and 10 years of age as compared to adults when performing a cognitive task, obtaining a longer center of pressure $(\mathrm{CoP})$ path length in children. Huang et al. (2003) obtained that children in the range between 5 to 7 years old decrease their gait speeds while performing concurrent cognitive tasks.

Some authors affirm that the degree of interference that causes the realization of dual tasks in children, varies according to the age of the child and the type of cognitive task that is carried out (Boonyong et al., 2012). In a recent study, Villarrasa-Sapiña et al., (2019) analyzed the development of postural control and the cost of the cognitive task on postural control during early childhood. The results of this work showed that during the performance of the dual-task the 4-year-old children had less postural control than the 5, 6 and 7-year-old children. Additionally, younger children had a lower performance in the cognitive task than those ages 6 and 7 . Olivier et al. (2010), conducted a study to clarify the effect of the dual-task on postural control in children from 7 to 11 years old and adults, and showed that around the age of 8 years the single postural task performance raised an adult-like level. Nevertheless, the management of the attentional resources did not reached the adult level until 11 years old. Palluel et al. (2010) obtained that in the accomplishment of a dual-task, adolescents between 12 and 15 years had worse punctuations in postural control variables (e.g. medio-lateral mean velocity and medio-lateral Root Mean Square) that adolescents of 16 and 17 years and adults, regardless of the complexity of the postural task. The authors attribute these differences to the inability to properly manage attention resources for the performance of two tasks simultaneously and to a limited capacity of information processing in young people under 14-15 years.

Regarding the type of cognitive task, Huang et al. (2003) compared the effects of different cognitive tasks (visual identification, auditory identification and memorization) in children between 5 and 7 years old. They obtained that the auditory identification task produced the greatest interference and the memorization task the smallest interference in the postural performance. Other studies vary the difficulty of the cognitive task, obtaining that the greater the difficulty of the cognitive task, the lower the cognitive performance (Olivier et al., 2010; Palluel et al., 2010). Olivier et al. (2010) assert that increasing the cognitive task difficulty implies postural modification only in children of 7 years but not in older children. Estevan et al. (2018) measured in adolescents between 13 and 16 years how the increase in the difficulty of the cognitive task affected the performance of the postural task, observing that as the cognitive requirements increased, the adolescents did not maintain their performance, both in balance and in cognition. At the same time, they observed that postural control and cognition maturate with age.

Although, research in the field of dual-task effect is increasing, is necessary to extend the literature about these effects in different children age groups, considering also the different types of cognitive task (i.e. arithmetic's, executive function, memory...) and different difficulty levels. As far as the authors know, there are no works that show the dual-task effects using a postural control and a memory tasks with different difficulty levels in middle childhood age groups.

For this reason, the main aim of this manuscript was to analyze the effect of dual task and their difficulty on the motor (postural control) and cognitive (memory) performance in middle childhood group ages children, establishing the differences between the effect of the tasks in the different age groups.

\section{Material and Methods}

\section{Participants}

One hundred and sixteen children, between 8 and 12 years old, participated in this study. The inclusion criteria were: i. participants had not prior experience with the experimental tasks, ii. to be between 8 and 12 years old (both inclusive) and iii. have not any motor control or neural pathology that could affect balance. The characteristics of the groups are shown in Table 1.

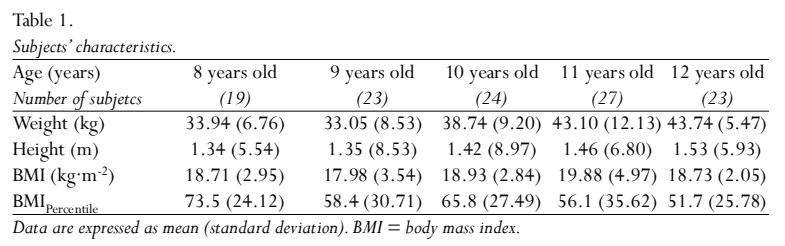


Previously, the study was approved by The Institutional Review Board of the University of Valencia. Subjects and their parents / guardians were informed regarding the nature and the aim of the study, and the parents/guardians of the participants signed an informed consent form.

\section{Procedure}

All the participants were evaluated at the school where they studied, in a noiseless room for avoid any interference in data collection process. First, weight and height were obtained. For this, the subjects were measured barefoot using a stadiometer SECA model 217 (Seca, Hamburg, Germany) and weighed on a bioelectrical impedance scale (Tanita BC-601). Before the evaluations, the subjects performed a familiarization session with the different tasks.

The participants completed three single tasks and two dual-tasks. Each subject performed a total of 5 trials of 35 seconds (one trial each task) with 60 seconds of rest between them, according with De Kegel et al. (2011) that describe this procedure as reliable to assess the postural stability in children.

Single tasks were of two types, postural and cognitive. The postural single task consisted in maintain the balance in the bipedal stance position. During bipedal stance, the subjects were barefoot with both feet parallel maintaining the heels separated by the width of the shoulders and toes pointing forward, with eyes open (EO) looking a reference point, with arms relaxed by sides and the subjects were informed to stand as still as possible for 35 seconds. The reference point $(5 \mathrm{~cm}$ in diameter) was situated $2 \mathrm{~m}$ in front of the subject at eye level. Otherwise, two cognitive tasks were performed: i. Backward Digit Span Test with 3-Digits sequences length (3D) and ii. Backward Digit Span Test 5 -Digits sequences length (5D). The digits sequences tests consisted of memorize a sequence of numbers and after say the number in inverse order (St ClairThompson \& Gathercole, 2006). During the 3D task, the students must memorize sequences of 3 numbers that appeared on a computer screen. Each number of the sequence was shown during $1000 \mathrm{~ms}$ and the time between numbers was of $100 \mathrm{~ms}$. Once the last digit of the sequence disappeared, the subject said the sequence in reverse order. During the time of the task, participants performed 6 sequences of 3D. During the 5D task, the process was the same that before but with sequences of 5 digits. In each trial of this task the participants performed in total 5 sequences. Finally, is important clarify that the cognitive tasks were performed in seated position.

The dual-tasks were the combination of the postural task and the cognitive tasks. The students should be in the bipedal stance and at the same time perform a cognitive test (3D or 5D sequences). The students were instructed to perform both tasks as good as possible. These tasks had a duration of 35 seconds each.

\section{Data collection and analysis}

Regarding the postural control measurement, CoP signals were acquired with a Wii Balance Board (WBB) that has been validated as an appropriate tool of analyzing postural control in the standing position in a number of studies. The data was acquired using WiiLab software (University of Colorado Boulder, Colorado, USA) for Matlab R2007 (Mathworks Inc, Natick, USA). Data signals were recorded at a frequency of $40 \mathrm{~Hz}$ and stored in a hard drive. After, the signals were filtered using a low pass Butterworth filter (cut-off frequency $=12 \mathrm{~Hz}$ ) in both the forward and reverse directions. The postural sway variables obtained from the $\mathrm{CoP}$ signals were the ellipse area (95\% confidence interval) and mean velocity in antero-posterior $\left(\mathrm{MV}_{\mathrm{AP}}\right)$ and medio-lateral $\left(\mathrm{MV}_{\mathrm{ML}}\right)$ directions. The ellipse area informs about the postural stability performance, and the $\mathrm{MV}_{\mathrm{AP}}$ and $\mathrm{MV}_{\mathrm{ML}}$ variables represents the net neuromuscular activity to maintain balance (Paillard \& Noé, 2015). In all cases, low values in these variables are associated to better performance in postural control tasks (Bermejo et al., 2015).

The data of the digit span task was acquired using backward digit span test free software. The number of correct digits were used a measure of the task performance. This variable was exported directly by means of the free software used.

\section{Statistical analysis}

SPSS software Version 24 (SPSS Inc., Chicago, IL, USA) was used for the statistical analysis. Nonparametric tests were used as Shapiro-Wilk test verified that some variables did not comply with the normality assumption. The median and inter-quartile range were obtained by standard statistical methods. To analyze the differences between age groups in postural control variables Kruskal-Wallis tests were performed followed by Dunn test with Bonferroni's correction. To analyze the effect of dual-task on postural control of each age independently, Friedman's Anova and Dunn test with Bonferroni's correction were applied. Finally, to analyze 
the effect of dual-task on cognitive performance of each age only Wilcoxon signed rank test was applied. The level of significance was set at $\mathrm{p}=.05$.

\section{Results}

\section{Postural control differences between age groups}

It was found an effect of age on ellipse in EO and 5D conditions $\left(\mathrm{c}_{4}^{2}=19.78 ; \mathrm{p}=.001\right.$ and $^{2}=17.97 ; \mathrm{p}=.001$, respectively), on $\mathrm{MV}_{\mathrm{AP}}$ in $3 \mathrm{D}$ and $5 \mathrm{D}$ conditions $\left(\mathrm{c}_{4}^{2}=10.73 ; \mathrm{p}=0.03\right.$ and $\mathrm{c}_{4}^{2}=20.64 ; \mathrm{p}<.001$, respectively) and on $\mathrm{MV}_{\mathrm{ML}}$ in $\mathrm{EO}, 3 \mathrm{D}$ and $5 \mathrm{D}$ conditions $\left(\mathrm{c}_{4}^{2}=15.94 ; \mathrm{p}=.003, \mathrm{c}_{4}^{2}=12.62 ; \mathrm{p}=.013\right.$ and $^{2}{ }_{4}=20.11$; $<.001$, respectively). Pairwise comparisons are showed in Table 2.

\begin{tabular}{|c|c|c|c|c|c|c|}
\hline & & 8-year-old & 9-year-old & 10-year-old & 11-year-old & 12-year-old \\
\hline \multirow{5}{*}{ Elipse $\left(\mathrm{mm}^{2}\right)$} & \multirow{2}{*}{ EO } & 185.96 & 112.94 & 156.48 & 90.76 & 64.94 \\
\hline & & $(127.10) * \dagger$ & (83.75) & $(179.87) \dagger$ & $(91.01)$ & $(86.53)$ \\
\hline & $3 \mathrm{D}$ & $\begin{array}{c}200.41 \\
(526.10)\end{array}$ & $\begin{array}{c}192.75 \\
(281.70)\end{array}$ & $\begin{array}{l}220.77 \\
(232.73)\end{array}$ & $\begin{array}{c}209.36 \\
(143.66)\end{array}$ & $\begin{array}{c}130.36 \\
(161.24)\end{array}$ \\
\hline & \multirow{2}{*}{$5 \mathrm{D}$} & 190.70 & 96.93 & 185.43 & 119.08 & 90.79 \\
\hline & & $(170.99) * \dagger$ & $(116.91)$ & $(140.25)$ & $(122.55)$ & (113.45) \\
\hline \multirow{5}{*}{$\begin{array}{c}\mathrm{MV}_{\mathrm{AP}} \\
(\mathrm{mm} / \mathrm{s})\end{array}$} & \multirow[t]{2}{*}{ EO } & 13.32 & 12.76 & 12.22 & $\begin{array}{r}9.90 \\
9681\end{array}$ & $\begin{array}{r}9.46 \\
(5.38)\end{array}$ \\
\hline & & 13.12 & $\begin{array}{l}(3.31) \\
14.13\end{array}$ & $\begin{array}{l}(5.40) \\
14.41\end{array}$ & $\begin{array}{l}(6.81) \\
12.55\end{array}$ & $\begin{array}{l}(5.38) \\
11.62\end{array}$ \\
\hline & $3 \mathrm{D}$ & $(6.01)$ & $(5.02) \dagger$ & (5.45) & (3.88) & $(4.01)$ \\
\hline & \multirow{2}{*}{$5 \mathrm{D}$} & 13.34 & 12.10 & 11.44 & 10.33 & 9.61 \\
\hline & & $(4.53) * \dagger$ & $(4.36) \dagger$ & $(3.94)$ & $(4.63)$ & (3.89) \\
\hline \multirow{6}{*}{$\begin{array}{l}\mathrm{MV}_{\mathrm{ML}} \\
(\mathrm{mm} / \mathrm{s})\end{array}$} & \multirow[t]{2}{*}{ EO } & 14.66 & 13.42 & 13.02 & 11.24 & 10.24 \\
\hline & & $(7.62) \dagger$ & (3.75) & $(8.56)$ & $(5.90)$ & $(4.24)$ \\
\hline & \multirow{2}{*}{ 3D } & 14.71 & 13.13 & 12.99 & 12.89 & 10.02 \\
\hline & & $(11.88) \dagger$ & $(4.91) \dagger$ & $(7.94)$ & $(4.29)$ & $(5.12)$ \\
\hline & \multirow{2}{*}{$5 \mathrm{D}$} & 13.29 & 11.90 & 11.39 & 10.31 & 9.01 \\
\hline & & $(7.67) * \dagger$ & $(3.49) \dagger$ & $(4.29)$ & $(4.99)$ & $(3.60)$ \\
\hline
\end{tabular}

\section{Effect of dual task in postural control}

In the 8 years old group there was not found an effect of dual-task on ellipse, $\mathrm{MV}_{\mathrm{AP}}$ nor $\mathrm{MV}_{\mathrm{ML}}$ ( $\mathrm{p}>$.05). In the 9 years group, we found an effect of dual-task on $\mathrm{MV}_{\mathrm{AP}}$ $\left(\mathrm{c}_{2}^{2}=12.09 ; \mathrm{p}=.002\right)$ and $\mathrm{MV}_{\mathrm{ML}}\left(\mathrm{c}_{2}^{2}=7.04 ; \mathrm{p}=.03\right)$. There was an effect of dual task on ellipse $\left(\mathrm{c}_{2}{ }_{2}=7.58\right.$; $\mathrm{p}=.02)$, the $\mathrm{MV}_{\mathrm{AP}}\left(\mathrm{c}^{2}=15.08 ; \mathrm{p}=.001\right)$ and the $\mathrm{MV}_{\mathrm{ML}}$ $\left(\mathrm{c}^{2}=12.25 ; \mathrm{p}=.002\right)$ in 10 years old children. In the case of 11 and 12 years we found an effect of the cognitive load in ellipse area $\left(\mathrm{c}_{2}=9.41 ; \mathrm{p}=.009\right.$ and $\mathrm{c}_{2}{ }_{2}=7.91$; $\mathrm{p}=.02$, respectively $), \mathrm{MV}_{\mathrm{AP}}\left(\mathrm{c}_{2}^{2}=14.74 ; \mathrm{p}=.001\right.$ and $\mathrm{c}_{2}^{2}=10.78 ; \mathrm{p}=.005$, respectively) and $\mathrm{MV}_{\mathrm{ML}}\left(\mathrm{c}_{2}{ }_{2}=14.74\right.$; $\mathrm{p}=.001$ and $\mathrm{c}^{2}=9.65 ; \mathrm{p}=.008$, respectively). Pairwise comparisons are showed in Figure 1.

\section{Effect of dual task on cognitive performance}

There were not differences between seated and standing position in the number of correct answers both in 3D and 5D conditions in any group of age (Figure 2).
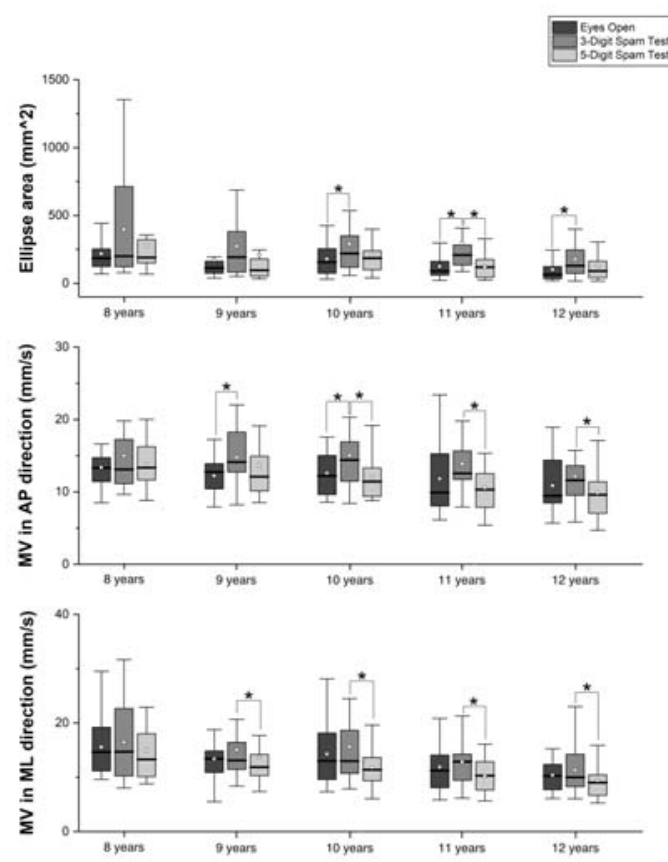

Figure 1. Postural control differences between conditions by age group. *Indicates statistical differences
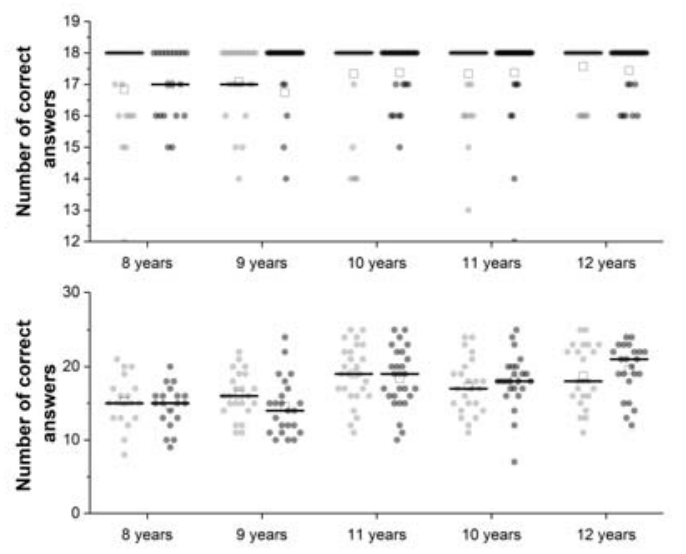

Figure2. Cognitive performance differences between single and dual-task conditions by age group. The upper graph corresponds to 3 Digits Spam Test and and the graph below corresponds to 5 Digits Spam Test. (Light grey $=$ single task performance; dark grey $=$ dual-task performance)

\section{Discussion}

The objective of the present study was to evaluate the interference of performing a dual task on motor and cognitive performance in children from 8 to 12 years old and analyze the postural control differences between the age groups in the studied conditions.

With regard to the postural control differences between the age groups, the pairwise comparisons showed that the 8 years old group had a worse performance in $\mathrm{EO}$ and 5D tasks than the 11 years old group. Additionally, also showed worse punctuations in all task compared with the 12 years old group. On the other hand, the 9-years-old only showed a worse performance than the 12 years old group in 3D and 5D tasks. 
Finally, the 10 years old group showed a worse performance in EO than 12 years old group. Thus, it seems the higher the children age the higher the postural control and performance.

Regarding dual task effect, cognitive performance did not change when children stand as still as possible compared with the reference condition (i.e., seated) in any of the two difficulty levels (i.e, 3- and 5-digits). Nevertheless, the worst postural control and performance was found in 3-digit condition revealing an interesting pattern that is discussed below. This finding was observed in children from 9 to 12 years old, but not in the youngest group of children (i.e., 8 years old children).

The analysis performed showed that the younger groups had worse punctuations in postural control variables in dual-task conditions than the older age groups, especially than the 12 years old group.

These results can be explained basically by the maturation level of subjects' motor control. Most studies in this field showed that the postural control and performance are enhanced as the children/adolescents grow (Estevan et al., 2018; Olivier et al., 2010; Palluel et al., 2010; Villarrasa-Sapiña et al., 2019). Thus, the results of our study are in the same line as scientific literature published until now. Focusing on the children of our study, it has been described that around 8 years old new postural control strategies are developed probably due to the maturation of the sensory systems involved in postural stability (Riach \& Starkes, 1993; Rival et al., 2004). Thus, it is possible that children from 8 to 12 years old enhanced their postural control and performance because they are improving these new strategies.

The results showed significant differences in the postural control exhibited by the groups of children between 9 and 12 years old in single task and 3D dualtask. In this case, it can be seen how the interference caused by the cognitive task coincides with the fact that the balance worsens. This also occurs in the group of 8 years old children, although in this case, the difference between motor performance under different conditions was not statistically significant probably due to the high variability of the data.

These results evidenced a cost in motor performance when a cognitive task was developed at the same time, phenomenon described previously works carried out in the field of motor behavior (Abuin-Porras et al., 2018; Estevan et al., 2018; Huang et al., 2003; Lacour et al., 2008). Interestingly, in all groups between 9 to 12 years old, higher postural control and stability were observed during the execution of the 5D dual-task than during the 3D task. That is, when a dual-task with a lower cognitive load was executed, the postural control and performance were lower, but when the cognitive load was higher, the motor performance levels did not differ from those shown during the single task execution.

In a study carried out with young adults, Riley et al. (2003) observed that the postural control was improved when the participants focused their attention on the memory task and dedicated less attentional resources to posture control, so that said postural control was automated. In the same way as in our study, postural control was better during the dual-task performance with high cognitive load than with low cognitive load.

McNevin \& Wulf (2002) explained in his work that the postural control of their participants was improved when they had focused their attention on an external focus, lending more attentional resources to said focus than to maintaining postural control. In addition, Vuillerme \& Nafati (2007) observed that focusing more resources to posture control caused the lower postural control.

Currently, the processes that operate in the distribution of cognitive and attentional resources are not yet completely clear, and the scientific community is debating around various theories (Lacour et al., 2008). However, it seems clear that the difficulty level of cognitive task during the dual-tasks execution as well as the shifts of the attentional focus between tasks influence on motor performance. For this reason, the participants of the present study could had perceived 5D task as more difficult than 3D task. So, they focus more attention and cognitive resources to $5 \mathrm{D}$ task than to $3 \mathrm{D}$ task even in dual-task condition. This fact could imply that during 5D dual-task a more external focus of attention was stablished than during the 3D dual-task.

Regarding the effect of dual task on cognitive performance, no differences were found in the number of correct answers in the cognitive task (3D and 5D) when performing a single or dual-task, in any age group. These results was different from those obtained by Huang et al. (2003), who affirmed that working memory performance decreased in dual-task conditions regarding singletask. Estevan et al. (2018) obtained results in the same line as Huang. In their case they used 3 cognitive tests similar to those used in the present study, with 3 levels of difficulty, 3, 5 and 7 digits. On the other hand, in the study carried out by Huxhold et al. (2006) with young adults it was observed that there was no decrease in 
cognitive performance while performing dual-tasks, which is in line with the results that we have obtained. As can be seen in figure 2, a ceiling effect was found in 3D condition. Thus, it seems that the cognitive tasks used resulted in a low functional difficulty for the participants of this study. In the future, scientific literature should play attention to set the cognitive tasks with different functional difficulties instead of nominal difficulties. Thus, the difficulty of the task will be set accordingly with the cognitive abilities of the participants.

\section{Conclusions}

In conclusion, children from 9 to 12 years old showed a lower postural control and performance during easy dual task than during single-task and hard dual-task conditions. The focus of attention of children during the execution seems to be a key point that should be taking into account in future studies. Finally, postural control and stability enhanced as children grow.

\section{Disclosure of interest}

The authors declare that they have no competing interest.(

\section{References}

Abuin-Porras, V., Villafañe, J. H., Jiménez-Antona, C., Palacios, A., Martínez-Pascual, B., \& RodríguezCosta, I. (2018). Relationship between attention and balance: A dual-task condition study in children. Journal of Exercise Rehabilitation, 14(3), 349-355. https: / / doi.org/10.12965/jer.1836142.071

Arce-Cifuentes, B., Bas-Cerdá, A., \& Garcia-Masso, X. (2020). Efectos de la auto-selección del foco de atención durante el aprendizaje de una tarea de control postural. Retos, 37, 93-99. https: / / doi.org/10.47197/ retos.v37i37.70875

Bermejo, J. L., García-Massó, X., Gomis, M., Noé, F., Huertas, F., Pablos, C., \& Paillard, T. (2015). The difficulty of postural tasks amplifies the effects of fatigue on postural stability. European Journal of Applied Physiology, 115(3), 489-495. https://doi.org/ 10.1007/s00421-014-3038-z

Blanchard, Y., Carey, S., Coffey, J., Cohen, A., Harris, T., Michlik, S., \& Pellecchia, G. L. (2005). The influence of concurrent cognitive tasks on postural sway in children. Pediatric Physical Therapy, 17(3), 189-
193.

Boonyong, S., Siu, K.-C., Donkelaar, P. van, Chou, L.S., \& Woollacott, M. H. (2012). Development of postural control during gait in typically developing children: The effects of dual-task conditions. Gait \& Posture, 35(3), 428-434. https://doi.org/10.1016/ j.gaitpost.2011.11.002

Bustillo-Casero, P., Cebrian-Bou, S., Cruz-Montecinos, C., Pardo, A., \& García-Massó, X. (2020). Effects of A Dual-Task Intervention in Postural Control and Cognitive Performance in Adolescents. Journal of Motor Behavior, 52(2), 187-195. https://doi.org/ 10.1080/00222895.2019.1600467

Bustillo-Casero, P., Villarrasa-Sapiña, I., \& García-Massó, X. (2017). Effects of dual task difficulty in motor and cognitive performance: Differences between adults and adolescents. Human Movement Science, 55, 8-17. https://doi.org/10.1016/j.humov.2017.07.004

Clark, J. E., \& Metcalfe, J. S. (2002). The mountain of motor development: A metaphor. Motor development: Research and reviews, 2(163-190).

De Kegel, A., Dhooge, I., Cambier, D., Baetens, T., Palmans, T., \& Van Waelvelde, H. (2011). Test-retest reliability of the assessment of postural stability in typically developing children and in hearing impaired children. Gait \& Posture, 33(4), 679-685. https: / / doi.org/10.1016/j.gaitpost.2011.02.024

Ebersbach, G., Dimitrijevic, M. R., \& Poewe,W. (1995). Influence of Concurrent Tasks on Gait: A Dual-Task Approach. Perceptual and Motor Skills, 81(1), 107-113. https: / / doi.org/10.2466/pms.1995.81.1.107

Estevan, I., Gandia, S., Villarrasa-Sapiña, I., Bermejo, J. L., \& García-Massó, X. (2018). Working Memory Task Influence in Postural Stability and Cognitive Function in Adolescents. Motor Control, 22(4), 425 435. https://doi.org/10.1123/mc.2017-0063

Goodway, J. D., \& Branta, C. F. (2003). Influence of a motor skill intervention on fundamental motor skill development of disadvantaged preschool children. Research quarterly for exercise and sport, 74(1), 36-46.

Holfelder, B., \& Schott, N. (2014). Relationship of fundamental movement skills and physical activity in children and adolescents: A systematic review. Psychology of Sport and Exercise, 15(4), 382-391.

Huang, H. J., \& Mercer, V. S. (2001). Dual-task methodology:Applications in studies of cognitive and motor performance in adults and children. Pediatric Physical Therapy: The Official Publication of the Section on Pediatrics of the American Physical Therapy Association, 13(3), 133-140. 
Huang, H.-J., Mercer, V. S., \& Thorpe, D. E. (2003). Effects of different concurrent cognitive tasks on temporal-distance gait variables in children. Pediatric Physical Therapy: The Official Publication of the Section on Pediatrics of the American Physical Therapy Association, 15(2), 105-113. https://doi.org/10.1097/ 01.PEP.0000067886.96352.6B

Huxhold, O., Li, S.-C., Schmiedek, F., \& Lindenberger, U. (2006). Dual-tasking postural control: Aging and the effects of cognitive demand in conjunction with focus of attention. Brain Research Bulletin, 69(3), 294305. https: // doi.org/10.1016/ j.brainresbull.2006.01.002

Lacour, M., Bernard-Demanze, L., \& Dumitrescu, M. (2008). Posture control, aging, and attention resources: Models and posture-analysis methods. Neurophysiologie Clinique/Clinical Neurophysiology, 38(6), 411-421. https://doi.org/10.1016/ j.neucli.2008.09.005

Lubans, D. R., Morgan, P. J., Cliff, D. P., Barnett, L. M., \& Okely,A. D. (2010). Fundamental Movement Skills in Children and Adolescents. Sports Medicine, 40(12), 1019-1035. https://doi.org/10.2165/11536850000000000-00000

McNevin, N. H., \& Wulf, G. (2002). Attentional focus on supra-postural tasks affects postural control. Human Movement Science, 21(2), 187-202. https:// doi.org/10.1016/S0167-9457(02)00095-7

Olivier, I., Cuisinier, R., Vaugoyeau, M., Nougier, V., \& Assaiante, C. (2010). Age-related differences in cognitive and postural dual-task performance. Gait \&Posture, 32(4), 494-499.https://doi.org/10.1016/ j.gaitpost.2010.07.008

Paillard, T., \& Noé, F. (2015). Techniques and Methods for Testing the Postural Function in Healthy and Pathological Subjects [Review Article]. BioMed Research International; Hindawi. https://doi.org/10.1155/ 2015/891390

Palluel, E., Nougier, V., \& Olivier, I. (2010). Postural control and attentional demand during adolescence. Brain Research, 1358, 151-159. https://doi.org/ 10.1016/j.brainres.2010.08.051

Riach, C., \& Starkes, J. (1993). Stability limits of quiet standing postural control in children and adults. Gait \&Posture, 1(2), 105-111. https:/ / doi.org/10.1016/ 0966-6362(93)90021-R

Riley, M. A., Baker, A. A., \& Schmit, J. M. (2003). Inverse relation between postural variability and difficulty of a concurrent short-term memory task. Brain Research Bulletin, 62(3), 191-195. https://doi.org/ 10.1016/j.brainresbull.2003.09.012

Rival, C., Ceyte, H., \& Olivier, I. (2004). Developmental changes of static standing balance in children. Neuroscience Letters, 376(2), 133-136. https:/ /doi.org/10.1016/j.neulet.2004.11.042

Schmid, M., Conforto, S., Lopez, L., \& D’Alessio, T. (2007). Cognitive load affects postural control in children. Experimental brain research, 179(3), 375-385.

Shumway-Cook, A., \& Woollacott, M. (2000). Attentional demands and postural control:The effect of sensory context. Journals of Gerontology-Biological Sciences and Medical Sciences, 55(1), M10.

St Clair-Thompson, H. L., \& Gathercole, S. E. (2006). Executive functions and achievements in school: Shifting, updating, inhibition, and working memory. Quarterly Journal of Experimental Psychology (2006), 59(4), 745-759. https://doi.org/10.1080/ 17470210500162854

Villarrasa-Sapiña, I., Estevan, I., Gonzalez, L.-M., Marco-Ahulló, A., \& García-Massó, X. (2019). Dual task cost in balance control and stability in children from 4-7 years old. Early Child Development and Care, O(0), 1-10. https://doi.org/10.1080/ 03004430.2019.1590349

Vuillerme, N., \& Nafati, G. (2007). How attentional focus on body sway affects postural control during quiet standing. Psychological Research, 71(2), 192-200. https://doi.org/10.1007/s00426-005-0018-2

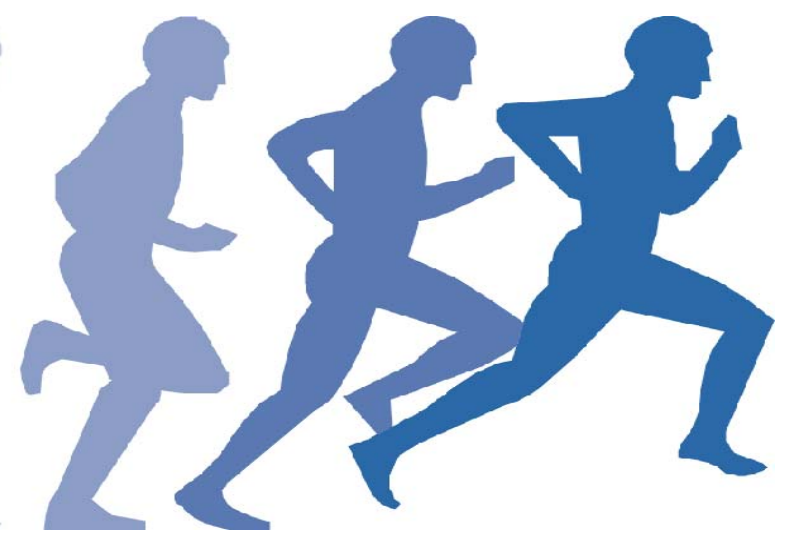

